\title{
Antenatal Screening for Assessing Obstetric Risk Factors at Kolta's Maternal and Child Health Center
}

\author{
Hanan Bolis Mored, Manal Farook Moustafa, Ghadah Abd-Elrahman Mahmoud \\ Nursing specialist-Technical Institute of Nursing - Assuit University \\ Assistant Professor of Obstetrics and Gynecological Nursing- Faculty of Nursing -Assiut University \\ Assistant Professor of Obstetrics and Gynecological Nursing - Faculty of Nursing - Assiut University
}

\begin{abstract}
:
Antenatal care ANC plays an important role in ensuring a healthy mother \& baby during pregnancy and after delivery. Aims of the study to assess the prevalence of low and high risk pregnant women at Kolta's Maternal and Child Health Center (MCHC), Medical and Obstetrical (Maternal\& fetal) risk factors among pregnant women at the same center. Subjects and methods descriptive research design was utilized in the present study, convenient sample was used among all prospective pregnant women who attended the Kolta's MCHC, sample size was 346 women, statistical record was from data base records of Kolta' s MCHC to gain the actual prevalence of low \& high risk pregnant women, structured interviewing questionnaire which developed by the investigator and included: Sociodemographic data, Obstetrical history, initial assessment, data related to high risk pregnancy, scoring system of high risk pregnancy. The study results revealed that $67.9 \%$ were in the of age group 20- 29 years old, $52 \%$ were living in rural areas, $71 \%$ were multigravidae, $23.6 \%$ had complications during last pregnancy, $86.2 \%$ had no medical history, $41.9 \%$ had anemia during pregnancy, $69.7 \%$ were high risk pregnancy, there are significant difference between weeks of gestation and anthropometric measurement $\mathrm{P}$ value $=0.021$ and significant difference between sociodemographic data and current antenatal care $\mathrm{P}$ value $=0.001$ Conclusion study concluded more than one third of the sample had anemia, the rate of high risk in the study was more than two thirds of the sample . Therefore, it is recommended to increasing pregnant women's awareness about ANC and risk factors during pregnancy, continuing Educational Nursing Programmes to access the high quality of care, new studies should be established.
\end{abstract}

Key Words: Antenatal care, Obstetrical\& Medical risk factors, Risk approach.

\section{Introduction:}

According to World Health Organization (WHO) estimates, more than 1,500 women die from pregnancy or childbirth-related complications every day. Annually, about half a million maternal deaths occur worldwide, and most of these deaths are in developing countries (WHO, 2008).

Antenatal care ANC coverage is a success story in Africa, since over two-thirds of pregnant women 69\% have at least one ANC contact (Jacob, A; 2009).

According to Egypt Demography and Health Survey EDHS, slightly more than one quarter of Egyptian pregnant women do not receive antenatal care. However, among those who receive antenatal care only one third of them received advised about signs of obstetrical complications and where and when to seek medical assistance (EDHS, 2008).

Egypt, MMR has declined dramatically from $174 / 100000$ live births in $1992-1993$ to $67.6 / 100000$ live births in 2005, a further decline to $44.6 / 100000$ was also reported in 2009. Egypt has scored a marked reduction in MMR, between 1992 and 2008, Approaching 68\% in all Egypt, 64\% in Lower Egypt and $72 \%$ in Upper Egypt (WHO, 2009).
Antenatal care is a preventive obstetric program aiming to getting pregnancy, labor and puerperium as near to normal as possible. One of the primary goals of antenatal care is to identify those women with raised risks for problems during pregnancy or delivery, in order to ensure that precautionary measures are instituted where possible or more intensive medical care is available when needed to this (Klossner and Hatfield, 2010).

Many health problems in pregnant women can be prevented, detected and treated during antenatal care visits with trained health workers. WHO recommends a minimum of four antenatal visits, comprising interventions such as tetanus toxoid vaccination, screening, treatment for infections and identification of warning signs during pregnancy (Barber, Sl; 2008).

The aim of prenatal screening is to identify the pregnant women who need going beyond surveillance and care over the basic care offered to all.(Goodwin, J, et al. 2009).

Antenatal care begins by initial visit, the aim of the first visit is to identify all risk factors .It includes: History (Menstrual, Obstetric, past history, medical, 
surgical and family history), Examination: (General examination, abdominal examination, pelvic examination), Investigation (screening tests) : (urine analysis for albumin, urinary tract infection, blood picture for hemoglobin , blood group, Rh typing, blood glucose screen, tests for hepatitis B, HIV, Syphilis, gonorrhea, Chlamydia, Rubella titer, pap smear screening and thyroid function screening. (Hodnett, 2009)

At subsequent antenatal visit, the following assessments are completed Weight, Blood Pressure, fundal height measurement, assessment for quickening and assessment of fetal heart rate (normal 110:160 beat/ minute) (Bottomlry\& Ryme, 2008).

The "risk approach" is a managerial tool for improving maternal and child health care. The risk assessment and classification of pregnant women into low risk and high risk groups has remained an integral component of most antenatal policies. Such antenatal policies ensure access to higher levels of care for at-risk pregnancies based on need (Nbaber\& Ckenny, 2011).

Risk factors include preexisting disorders, physical and social characteristics, age, problems in previous pregnancies (e.g., spontaneous abortion), and problems that develop during the pregnancy or during labor (Wong\& Perry, 2008).

The WHO has devised a simple scoring system which can be modified for local use when assessing the risk status of a pregnancy the scoring system takes into consideration maternal characteristics such as age, number of children, time since last delivery, medical history, and maternal education, referral to appropriate levels of care is obligatory for those women who have high risk pregnancy. A simple scoring system assigns different points to different maternal characteristics of interest: age $(<19$ or $>40$ years 4 points; 30-39 years scores 2 points; 20- 29 years scores zero); number of children ( $>10$ children scores 4 points; $0-1$ child scores 2 points; 2-9 children scores zero); medical history (previous obstetrical complications and perinatal deaths scores 3points, diabetes, heart disease, renal disease, psychosis scores 5 points) and maternal education (illiterate scores 1 point, literate scores zero). The scoring system place pregnant women with aggregate points 3- 4 as high risk and those with points $0-2$ as low risk (Oyibo, et al., 2011)

The Maternal and Child Health Care Centers (MCHCs) collaborate with public hospitals to establish a comprehensive antenatal shared-care programmer to monitor the whole pregnancy and delivery process. Expectant mothers receive checkups at scheduled intervals, routine blood tests, related health advice and counseling. (ARE, MOHP, 2009).
So Maternal mortalities are mostly preventable, especially those related to direct causes. Access of pregnant mothers to skilled care during delivery and provision of emergency obstetric care when necessary, have contributed to diminished levels of maternal mortality (EDHS, 2008).

\section{Significance of the Study}

Approximately 500.000 births that occur worldwide each year are categorized as high risk because of maternal or fetal complication. Perinatal outcomes depend on the early recognition and management of problems, identification of the risks, together with appropriate and timely intervention during the perinatal period, can prevent morbidity and mortality among mothers and infants (Wong\& Perry, 2008).

In Egypt 2010, 287,000 women died of pregnancyrelated causes. The number of maternal deaths ranges from an average of 16 per 100,000 live births in the world's most developed countries to over 1,000 per 100,000 live births in the world's least developed countries, twenty-nine maternal deaths were identified among 8656 pregnant women residing in Assiut city (Upper Egypt). (WHO, 2010)

To identify women at high risk of complications in a current pregnancy, in order to refer them for care by personnel or centers suitably equipped to prevent maternal and neonatal morbidity and mortality. An adverse Obstetric history is an excellent indicator of risk in a current pregnancy

\section{Research questions:}

- What are the Obstetric \& medical risk factors at Kolta's MCHC?

- What are The prevalence of low and high risk pregnant women at Kolta's MCHC?

\section{Aims of the Study were:}

\section{1- General objectives:}

- To assess the prevalence of low and high risk pregnant women at Kolta's MCHC.

- To assess Medical and Obstetrical (Maternal\& fetal) risk factors among pregnant women at Kolta's MCHC.

\section{2- Specific objectives:}

- To assess type of medical \& Obstetric risk factors.

- To assess rate of low \& high risk factors.

Subject and Methods:

Research design: descriptive design was utilized in the present study.

Setting:

The study was conducted in Kolta' s MCHC in Assiut city.

\section{Sample size:}

Random sample was used among all prospective pregnant women who attended the Kolta's MCHC at Assiut city by using Epi- info version 3.3 with power 
$80 \%$, CI $95 \%$, and expected prevalence of $55 \%$, worst acceptable $60 \%$ so sample size was 346 .

\section{Tools:}

Part I

* Statistical record was constructed to be completed from data base records of Kolta' s MCHC; the data collected in the statistical record included the following:

- Total number of pregnant women/month for one year to gain the actual prevalence of low (normal) $\&$ high risk pregnant women at $\mathrm{MCHC}$.

Part II

* Structured interviewing questionnaire which developed by the investigator and included the following data:

1. Sociodemographic data (e.g. name, age, residence, education...)

2. Obstetrical history (e.g. gravidity, parity, still birth, neonatal death, number of living children ...........)

3. Initial assessment:-

- Measurement (e.g.: weight, height, Body Mass Index BMI)

- The actual routine investigations done at MCHC: (complete blood count, blood type and antibody screen, urine analysis for sugar, protein, ultrasonography).

- Current antenatal condition.

- Weeks of gestation.

o First trimester

o Second trimester

o Third trimester

4- Data due to high risk pregnancy (Maternal Medical risk Factors, Obstetrical risk factors \{maternal and fetal\}, special Investigations in the presence of high risk factors, type of risk Factors \{Medical or Obstetrical\}, investigations, vaccinations done For women and schedule antenatal care for \{low and High risk groups .

\section{Part III:}

A simple scoring system assigns different points to different maternal characteristics of interest: age (<19 or $>40$ years 4 points; $30-39$ years scores 2 points; 20- 29 years scores zero); number of children (>10 children scores 4 points; 0 - 1 child scores 2 points; 2 9 children scores zero); medical history (previous obstetrical complications and perinatal deaths scores 3points, diabetes, heart disease, renal disease, psychosis scores 5 points) and maternal education (illiterate scores 1 point, literate scores zero). The scoring system place pregnant women with aggregate points 3-4 as high risk and those with points $0-2$ as low risk

\section{Ethical considerations:}

The purpose and nature of the study was explained to the directors and take a copy from protocol to obtain their permission. The purpose of study explained to pregnant women who agreed to participate in the study, they were free to ask any question about the details of the study and have right to withdrawal at any time. Confidentiality of obtained information insured and achieved by the use of locked files and the names of the participating pregnant women replaced by numbers.

\section{Procedure:}

This study carried out in 3 phases:

1-Preparatory phase: A review of current, past, local and international related literature in the various aspects of the problem using books, articles, periodical magazines and websites were done and this ended by a pilot study.

2-Pilot study phase: Was done for $10 \%$ of pregnant women from the sample subjects to evaluate validity and reliability of the tools, these cases were excluded from the study.

\section{3- Actual study phase:}

\section{Procedure:}

O An official permission was obtained from the Dean of the Faculty of Nursing directed to deputy manager of Kolta's MCHC in Assiut City. All pregnant women were attending the Kolta's MCHC were recruited in this study.

o The investigator collected the sample through two days every week, the investigator went to Kolta 's $\mathrm{MCHC}$ at 9:00 Am, The investigator introduced to the nurses who assisted to collect the data and then introduced to all pregnant women who agreed to participate in the study,

\section{Before entering the Examination room:}

o The investigator explained the purpose of the study to the women and invited them to participate in the study; those women who agreed to participate in the study gave a (written/verbal) informed consent after clear explanation of the purpose of the study and there was no additional risk or cost in participation.

o The investigator interviewed each woman separately, obtained the sociodemographic data: (name, age, residence, education), Obstetrical and Medical history: (gravidity, parity, still birth, neonatal death, number of living children). Data due to current pregnancy if there is any risk factors (Maternal, Fetal), provided general health education about antenatal care such as, ANC schedule visits, its importance, importance of continuing in follow up, warning signs, antenatal advices e.g. hygienic care during pregnancy, perineal care, breast feeding, different family planning methods, importance of spacing between 
children), provided specific health education according Medical or Obstetrical risk factors such as: importance of follow up with medical physician in case of pre-gestational diabetes or hypertension, regular check up to detect any deviation from normal and referral system.

\section{At Examination room:}

○ The investigator measured blood pressure, weight, height for each pregnant woman and listened to each woman during physical, abdominal, ultrasound examinations. participated in management which is done for each pregnant woman and according to her condition (by helping the pregnant woman to recognized her condition, if any requested investigation advice the women to complete it in laboratory and bring results to the Obstetrician\& interpret her laboratory investigations in clear explanation, how to take prescribed medications, encouraged asking any question about her condition and reinforced time of the next visit.

o Finally the investigator recorded the Medical and Obstetrical risk factors if present for those pregnant women.

\section{Results:}

Table 1 Distribution of study subjects by sociodemographic characteristics:

\begin{tabular}{|c|c|c|}
\hline Sociodemographic characteristics & Frequency $(\mathrm{No}=346)$ & $\%$ \\
\hline \multicolumn{3}{|l|}{ 1-Mother age } \\
\hline$<20$ & 20 & 5.8 \\
\hline $20-29$ & 235 & 67.9 \\
\hline $30-39$ & 82 & 23.7 \\
\hline $40+$ & 9 & 2.6 \\
\hline$($ mean + SD $)$ & \multicolumn{2}{|l|}{$26.5+5.2$} \\
\hline \multicolumn{3}{|l|}{ 2-Residence } \\
\hline Rural & 180 & 52 \\
\hline Urban & 166 & 48 \\
\hline \multicolumn{3}{|l|}{ 3-Education level } \\
\hline Illiterate & 110 & 31.8 \\
\hline Read and write & 15 & 4.3 \\
\hline Primary education & 10 & 2.9 \\
\hline Preparatory education & 32 & 9.2 \\
\hline Secondary education & 133 & 38.4 \\
\hline University & 46 & 13.3 \\
\hline \multicolumn{3}{|l|}{ 4-Mother occupation } \\
\hline House wife & 303 & 87.6 \\
\hline Employed & 43 & 12.4 \\
\hline
\end{tabular}

\section{Pilot Study:}

It is done for $10 \%$ of pregnant women from the sample to evaluated validity and reliability of the tools, these cases were excluded from the study.

Limitation of the study:

Stop working for 3 months because sit of doctors at Kolta' s MCHC to request their rights.

\section{Statistical analysis:}

Statistical package for social sciences (SPSS) statistical software version 16 logistic regression analysis was used in this study. Data collected were coded and analyzed. The results were presented using descriptive statistics in the form of frequencies and percentages for qualitative variables and means and standard deviations for quantitative variables. A significant P-value was considered when it is less than or equal. 
Table: (2) Distribution of study subjects by their obstetrical history

\begin{tabular}{|c|c|c|}
\hline Obstetric history & Frequency $(\mathrm{N}=346)$ & $\%$ \\
\hline 1-Gravidity mean + S D & \multicolumn{2}{|c|}{$2.2+1.3$} \\
\hline Primigravdiae & 101 & 29 \\
\hline $1-2$ & 212 & 60.4 \\
\hline $3-4$ & 31 & 10 \\
\hline $5+$ & 2 & 0.6 \\
\hline 2-Stillbirth mean \pm S D & \multicolumn{2}{|c|}{$1.1 \pm 0.4$} \\
\hline Zero & 339 & 98.0 \\
\hline $1-2$ & 7 & 2.0 \\
\hline 3-Neonatal death mean + S D & \multicolumn{2}{|c|}{$1.5 \pm 0.7$} \\
\hline Zero & 344 & 99.4 \\
\hline $1-2$ & 2 & 0.6 \\
\hline 4-No of living children males mean $\pm \mathrm{S}$ D & \multicolumn{2}{|c|}{$1.3 \pm 0.6$} \\
\hline 1 & 117 & 33.8 \\
\hline $2-3$ & 41 & 11.8 \\
\hline No of living children females & \multicolumn{2}{|c|}{$1.7 \pm 1$} \\
\hline 1 & 116 & 33.5 \\
\hline $2-3$ & 59 & 17.1 \\
\hline $4+$ & 13 & 3.8 \\
\hline 5-Abortion mean +S D & \multicolumn{2}{|c|}{$1.2+0.6$} \\
\hline None & 332 & 95.9 \\
\hline 1 & 12 & 3.5 \\
\hline 2 & 1 & 0.3 \\
\hline $3+$ & 1 & 0.3 \\
\hline
\end{tabular}

Table: (3) Distribution of study subjects according to Medical history

\begin{tabular}{|l|c|c|}
\hline \multicolumn{2}{|c|}{ Medical history } & Frequency $(\mathbf{n}=\mathbf{3 4 6})$ \\
\hline 1-Maternal problems & 298 & \% \\
\hline None & 5 & 86.2 \\
\hline Cardiovascular diseases & 2 & 1.4 \\
\hline Hypertension diseases & 4 & 0.6 \\
\hline Renal diseases & 5 & 1.2 \\
\hline Respiration diseases & 1 & 1.4 \\
\hline Gastro intestinal diseases & 5 & 0.3 \\
\hline Diabetes mellitus & 23 & 1.4 \\
\hline Others & 3 & 6.6 \\
\hline More than one risk factors & & 0.9 \\
\hline
\end{tabular}


Figure (1-A) Distribution of pregnant women according to Maternal risk factors

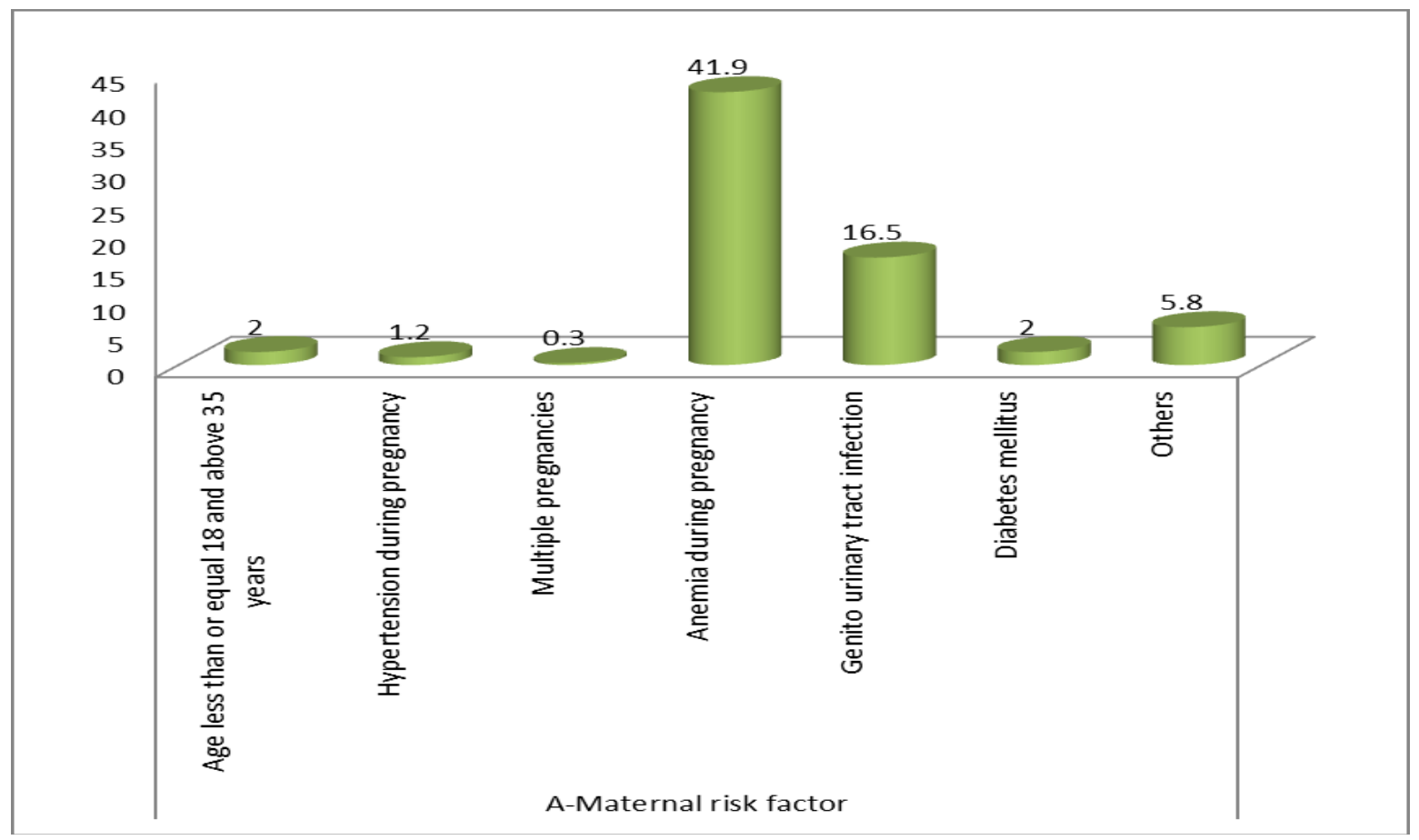

Figure (1-B) Distribution of study subjects according to fetal risk factors

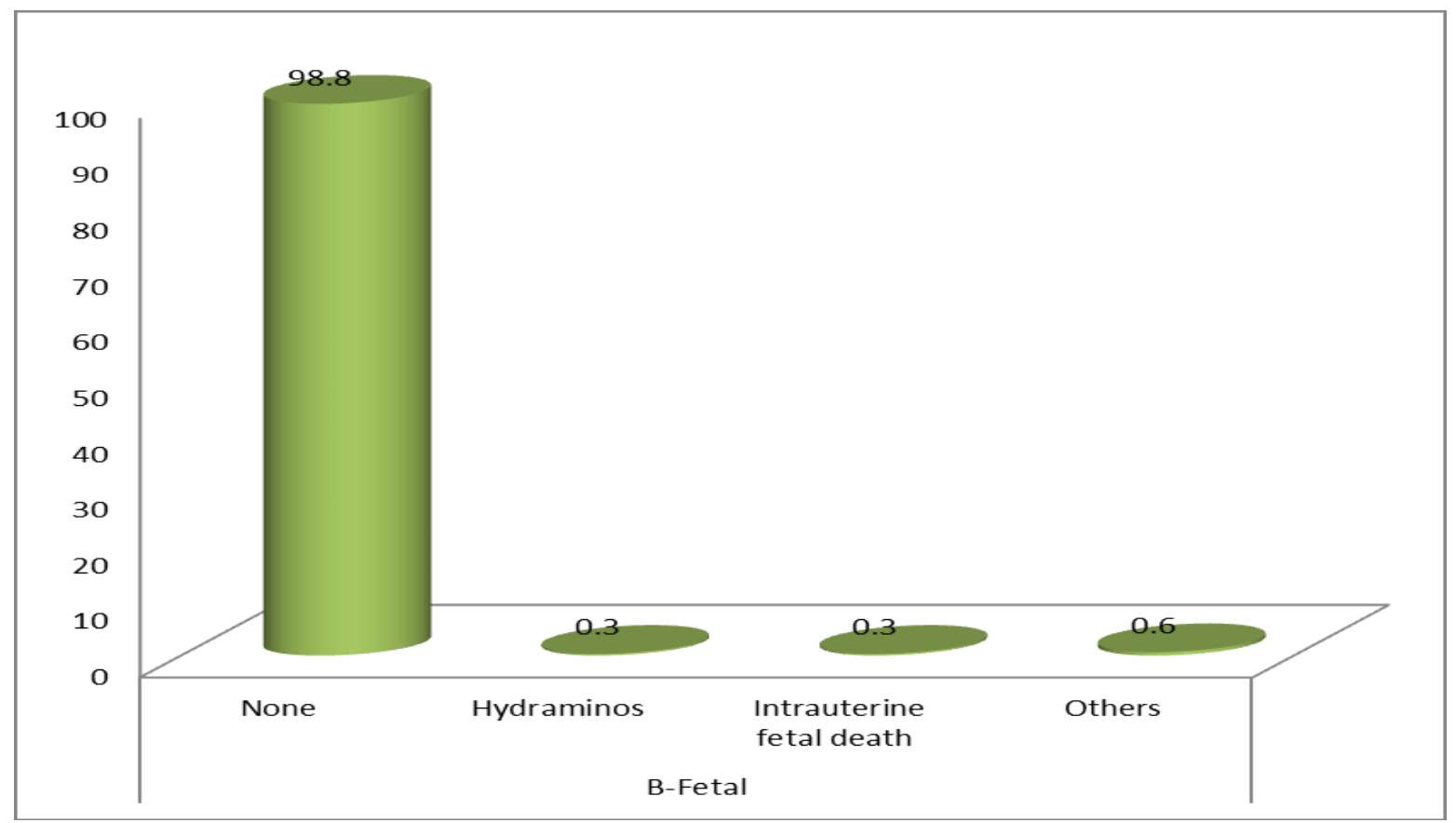

Table: (4) Distribution of study subjects according to Current antenatal condition:

\begin{tabular}{|l|c|c|}
\hline Current antenatal condition & Frequency $(\mathbf{N}=\mathbf{3 4 6})$ & \% \\
\hline High risk & 241 & 69.7 \\
\hline Low risk(Normal) & 105 & 30.3 \\
\hline
\end{tabular}


Figure: (2) Distribution of study subjects according to Current antenatal condition.

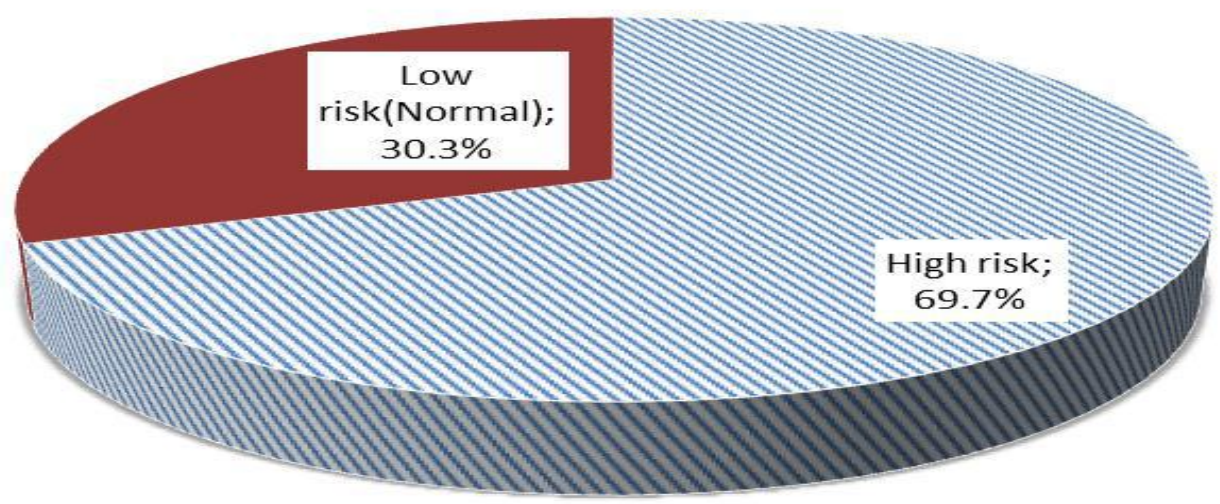

Table: (5): Relationship between sociodemographic data and current antenatal condition:

\begin{tabular}{|c|c|c|c|c|c|}
\hline \multirow{2}{*}{ Sociodemographic characteristics } & \multicolumn{2}{|c|}{ High risk $(\mathrm{n}=241)$} & \multicolumn{2}{|c|}{ Low risk $(\mathrm{n}=\mathbf{1 0 5})$} & \multirow{2}{*}{ P. value } \\
\hline & $\mathbf{N}$ & $\%$ & $\mathbf{N}$ & $\%$ & \\
\hline $\begin{array}{l}\text { 1-Maternal age } \\
(\text { mean+ SD) }\end{array}$ & \multicolumn{2}{|c|}{$28.9+4.5$} & \multicolumn{2}{|c|}{$24.3+3.7$} & $0.001 * *$ \\
\hline$\square<20$ & 17 & 7.1 & 3 & 2.9 & \multirow{4}{*}{$0.001 * *$} \\
\hline$\square \quad 20-29$ & 135 & 56.0 & 100 & 95.2 & \\
\hline$\square \quad 30-39$ & 80 & 33.2 & 2 & 1.9 & \\
\hline$\square \quad 40+$ & 9 & 3.7 & 0 & 0.0 & \\
\hline \multicolumn{6}{|l|}{ 2-Residence } \\
\hline$\square \quad$ Rural & 165 & 68.5 & 15 & 14.3 & \multirow{2}{*}{$0.001 * *$} \\
\hline$\square \quad$ Urban & 76 & 31.5 & 90 & 85.7 & \\
\hline \multicolumn{6}{|l|}{ 3-Education level } \\
\hline$\square \quad$ Illiterate & 100 & 41.5 & 10 & 9.5 & \multirow{6}{*}{$0.001 * *$} \\
\hline$\square \quad$ Read and write & 12 & 5.0 & 3 & 2.9 & \\
\hline$\square$ Primary education & 8 & 3.3 & 2 & 1.9 & \\
\hline$\square$ Preparatory education & 12 & 5.0 & 20 & 19.0 & \\
\hline$\square \quad$ Secondary education & 99 & 41.1 & 34 & 32.4 & \\
\hline$\square \quad$ University & 10 & 4.1 & 36 & 34.3 & \\
\hline \multicolumn{6}{|l|}{ 4-Mother occupation } \\
\hline$\square$ House wife & 236 & 97.9 & 67 & 63.8 & \multirow{2}{*}{$0.001 * *$} \\
\hline$\square$ Employed & 5 & 2.1 & 38 & 36.2 & \\
\hline
\end{tabular}

Table (6)The relationship between weeks of gestation and anthropometric measurements

\begin{tabular}{|l|c|c|c|c|}
\hline \multirow{2}{*}{$\begin{array}{c}\text { Weeks of gestation } \\
\text { Anthropometric Measurements }\end{array}$} & \multicolumn{3}{|c|}{ Mean \pm SD } & \multirow{2}{*}{ P. value } \\
\cline { 2 - 5 } & $\mathbf{1}^{\text {st }}$ trimester & $\mathbf{2}^{\text {nd }}$ trimester & $\mathbf{3}^{\text {rd }}$ trimester & \\
\hline Height & $156.9 \pm 4.6$ & $157.1 \pm 3.9$ & $157.1 \pm 3.9$ & 0.926 \\
\hline Weight & $66.9+10$ & $68.9+6.4$ & $73.2+7.2$ & $0.021^{*}$ \\
\hline BMI & $27.4 \pm 3.9$ & $28 \pm 2.9$ & $28.1 \pm 3.1$ & 0.439 \\
\hline SBP & $112.2 \pm 8.5$ & $114.7 \pm 8.9$ & $115.7 \pm 11.9$ & 0.157 \\
\hline DBP & $77.2 \pm 6.5$ & $77.4 \pm 6.1$ & $77.8 \pm 7.2$ & 0.824 \\
\hline
\end{tabular}


Table 1: shows that more than two thirds of the study subjects $67.9 \%$ were in the age group 20- 29 years old, with the mean age of $26.5 \pm 5.2$. As regards education, more than one third of sample $38.4 \%$ were secondary educated, whereas one third of them $31.8 \%$ were illiterate, slightly more than half of them $52 \%$ were living in rural areas and the majority of women $87.6 \%$ were housewives.

Table 2: Concerning Obstetrical history this table shows that more than two thirds of sample $71 \%$ was multigravidae, while only $29 \%$ were primigravidae; the mean of gravidity was $2.2 \pm 1.2$. Regarding to history of stillbirth the majority of the sample had no a history of stillbirth, and neonatal deaths $98 \% \&$ $99.4 \%$ respectively. Concerning history of abortion, majority of the sample $95.9 \%$ had no a history of abortions. concerning the history of living children, nearly third of sample had a history of one male and one female $33.8 \%$ and $33.5 \%$ respectively.

Table 3: Concerning distribution of study subjects according to medical history, Table 3 shows that the majority of sample $86.2 \%$ had no medical history.

Table 4: shows nearly two thirds of the sample $(69.7 \%)$ were classified as high risk pregnancy, while nearly one third of the sample $(30.3 \%)$ classified as low risk pregnancy.

Table 5: concerning relationship between sociodemographic data and current antenatal condition table 5 shows that there are significant difference between two variables, $\mathrm{p}$ value $=0.001$.

Table 6: Concerning relationship between weeks of gestation and anthropometric measurement, as regarding to weight table 6 shows that there are significant difference between variables, $P$ value $=0.021$.

Figure 1:A, B: shows more than one third of the study subjects $41.9 \%$ had anemia during pregnancy. Whereas nearly one third of the sample $30.3 \%$ had no maternal risk factors. As regard to fetal risk factor, figure 1- B shows that vast majority of the sample $98.8 \%$ had no fetal risk factor.

Figure 2: shows nearly two thirds of the sample $69.7 \%$ were classified as high risk pregnancy, while nearly one third of the sample $30.3 \%$ classified as low risk pregnancy

\section{Discussions:}

Screening and monitoring in pregnancy are strategies used by health care providers to identify high risk pregnancies so that they can provide more targeted and appropriate treatment and follow up care and to monitor fetal well-being in both low and high risk pregnancies. (Habib, F; et al. 2009)

The aims of this study to assess: the prevalence of low and high risk pregnant women at Kolta's MCHC,
Medical and Obstetrical (Maternal\& fetal) risk factors among pregnant women at the same center. Antenatal care prevalence according to the statistical data obtained from Kolta 's MCHC in the present study during the previous year (2012), the overall population rate of ANC was 548, more than half of the total categorized as low risk pregnancy and less than half of the total categorized as high pregnancy.

Regarded to sociodemographic characteristics of the study subjects table 1 , the results of the present study revealed that the age of sample from 17- 40 with mean age $\pm \mathrm{SD}(26.5+5.2)$, it also revealed that more than two thirds of the sample were in the age group of 20-29 years old, this findings consistent with the result of the study conducted in Ethiopia, by Alem, M; 2013 who reported in his study (factors affecting the utilization of antenatal care services in Ibadan, Nigeria) that about the mean age participants was $26.4 \pm 0.12$ in age group ranged from $18-40$ years.

Regarded to place of residence, the present study revealed that more than the half of the study subjects were living in rural areas versus nearly half of the sample were living in urban areas, this finding contracting with study conducted by Alam, et al. 2013 those reported in their study (disparities in the use of antenatal care service in Ethiopia over a period of fifteen years) that about majority of the study subjects were from rural area, in addition, this finding contracting with study conducted by Habib, F; et al. 2009 those mentioned in their study (antenatal care in primary health care centers, medina, Saudi Arabia) that about nearly one third of the sample lived in rural areas while two thirds of the sample were lived in urban areas.

According to educational level of the study subjects in the present study revealed that more than one third of the sample $38.4 \%$ had secondary education versus less than one third of the sample were illiterate, the results consistent with study conducted by Habib, F; et al. 2009 those reported in their study (antenatal care in primary health care centers, medina, Saudi Arabia) that about more than one third of the sample got secondary education, this findings contracting with the study conducted by Alam, et al. 2013those reported in their study (factors affecting utilization of antenatal care among women in urban Sulum areas of Islamabad) that about majority of the sample were illiterate.

As regarded to mother's occupation, the present study revealed that majority of the study subjects were housewives this appear in increase rate of high risk pregnancy. This result consistent with study conducted by Habib, F; et al., 2009 those reported in their study (antenatal care in primary health care centers, medina, Saudi Arabia) that majority of the sample were housewives. 
Concerned the Obstetrical history table 2, the present study revealed that more than two thirds of the sample were multigravidae, this result ensure on multi parity increase risk during pregnancy, while less than one third of the sample were primigravidae. The mean of gravidity was $2.2+1.3$.

As regarded to gravidity the present study supported by study conducted in rural Kenya by Weiner, R; et al. 2013 those reported in their study (labor complications remain the most important risk factors for perinatal mortality in rural Kenya) that about less than one third of the study subjects primigravidae, while more than two thirds of the sample were multigravidae.

As regarded to neonatal deaths history, the present study shows that vast majority of the sample had no history of neonatal deaths, This finding consistent with the study conducted by Zareen, N; et al. 2009 those reported in their study (perinatal outcomes in high risk pregnancies) that about $(3.08 \%)$ had a history of neonatal deaths, and inconsistent with the study conducted by Anne, M; et al. 2006 those found in their study (use of antenatal services and delivery care among pregnant women rural western Kenya: a community based survey) that about less than two thirds of study subjects had no history of neonatal deaths.

Concerned history of abortion, the present study revealed that vast majority of the sample had no history of abortions, this finding consistent with the study conducted by Upadhyay, C; et al. 2013 those found in their study (obstetrical outcomes of pregnancies following abortion) that about majority of the study subjects had no previous history of abortion, on the other hand, inconsistent with study conducted by Tebeu, P; et al., 2011 those found in their study (risk factors for hypertensive disorders in pregnancy: a report from the Maroua regional Hospital, Cameron) that about less than two thirds of the study subjects had history of abortions.

As regarded to maternal risk factors figure (1-A) in the present study shows that more than half of the sample had maternal risk factors (anemia, Genito urinary tract infection), this finding inconsistent with the study conducted by Upadhyay, C; et al. 2013 those reported in their study (Obstetrical outcomes of pregnancies following abortions) that about nearly half of the of study subjects had maternal risk factors, and with study conducted by Tuladhar, H; et al., 2011 those reported in their study (impact of antenatal care on maternal and perinatal outcomes a study of Nepal Medical College Teaching Hospital) that about one quarter of the study subjects had medical complications.

As regarded to prevalence of anemia, the present study revealed that more than one third of the study subjects had anemia during pregnancy due to lack of iron intake, malabsorbed of iron and increases physiological demands during pregnancy (twins, multipara), this finding nearly consistent with the study conducted by Kalaivani, K; 2009 who reported in his study (prevalence \& consequences of anemia in pregnancy) that about less than half of the sample had anemia during pregnancy, in addition, contracting with the study conducted by Nicholas, et al., 2012 those reported in their study (Quality of antenatal care in Zambia: a national assessment) that about less than one quarter of the study subjects had anemia during pregnancy.

As regarded to fetal risk factors figure (1-B) in the current study revealed that vast majority of the study subjects had no fetal risk factor, this finding contracting with the study conducted by Upadhyay, C; et al. 2013 those reported in their study (Obstetrical outcomes of pregnancies following abortions) about more than one third of the study subjects had fetal risk factors.

As regarded to classifications of the study subjects according to current ANC condition (figure 2, table 4 ) in the present study revealed that more than two of the study subjects classified as high risk pregnancy while the other one third of the study subjects classified as low risk pregnancy. This finding due to lack of awareness by importance of follow up during antenatal period, ignorance of the pregnant women about warning signs and maternal, fetal risk factors during pregnancy.

These data consistent with study conducted by Kashani, E; et al. 2012 those reported in their study (the rate of the prevalence of high risk pregnancies and the results on pregnant mothers and the effect on parameters after the birth) that nearly two thirds of study subjects had high risk pregnancy and more than one third of the sample had low risk pregnancy, In addition, contracting with studies conducted by Zareen, N; et al. 2009 those reported in their study (perinatal outcomes in high risk pregnancies)\& Tran, T; et al. 2012 those found in their study (factors associated with antenatal care adequacy in rural and urban context - results from two health and demographic surveillance sites in Vietnam)\& Eswi, A., and Kalil, A., 2012 those found in their study (health locus of control among low risk and high risk pregnant women) that about more than half of the sample had high risk pregnancy and less than one half of the sample had low risk pregnancy\& nearly one quarter of the sample had high risk pregnancy and nearly two thirds of the sample had low risk pregnancy\& less than half of the sample had high risk pregnancy and more than half of the sample had low risk pregnancy respectively. 
Concerned relationship between sociodemographic data and current of antenatal care table 5 the present study shows that there significant difference between two variables $=0.001$.

Concerning relationship between weeks of gestation and anthropometric measurement table 6 , the present study shows that there are significant difference between weight during different trimesters ( $P$ value $=0.021$ ) this because weight gain during pregnancy $(9-12 \mathrm{~kg})$.

\section{Conclusions:}

Based on the present study findings, it can be concluded that: more than two thirds of the sample in age group (20-29), more than one fifth of the sample had complications during last pregnancy, three quarters of the sample had no complications during last delivery, majority of the sample had no maternal medical problems, one third of the sample had no maternal (obstetric) risk factors while about more than one third of the sample had anemia during pregnancy, the rate of high risk pregnancy in the present study was more than two thirds of the study subject . The study approved that there are significant difference among weeks of gestation and anthropometric measurements (weight) $\mathrm{p}$ value $=$ $0.021 \&$ sociodemographic data and current of antenatal care $\mathrm{p}$ value $=0.001$.

\section{Recommendations:}

In the light of the findings of the present study, the following recommendations are suggested:

- Increasing pregnant women's awareness about antenatal care and risk factors during pregnancy.

- New studies should be established to follow up the prevalence of obstetrical risk factors and its consequence on both maternal and fetal outcomes.

Future recommendation:

- Continuing Educational Nursing Programmes about the antenatal care should be designed and taught by expert nursing staff to access the high quality of care.

\section{References:}

1. Anne, M., V; Hanneke, M., B; Frankodhiambo; John, G., A; Illse, E., B; Daniel, H., R; Kubaje, A; Laurence, $S$ and Kim, A L: (2006): Use of antenatal services and delivery care among women in rural western Kenya: a community based survey, http:// www.reproductive - health - journal.com/ content/3/112.

2. Arab Republic of Egypt, Ministry of Health and Population, Basic Essential Obstetric Care:
Protocols for Physicians (Cairo, June, 2009), ch $(5,6)$, Standards of Practice for Integrated MCH/RH Services, 2nd Edition : 190-200.

3. Alem, M; Enawgaw, B; Gelaw, A; Tigistkena; Seid, M and Y Olkeba, Y. (2013): Prevalence of anemia and associated risk factors among pregnant women attending antenatal care in Azezo Health Center Gondar town, Northwest Ethiopia: J. interdiscipt Histopathol 2013; 1 (3): 137- 144.

4. Alam, A., Y; Qureshi, A, A; Adil, M, M and Hasan Ali; (2013): Factors affecting utilization of antenatal care among women in urban slum areas of Islambad.

5. Barber, SL; (2008): Comparative evaluation of the effectiveness and safety of women, Volume 66: 269-73.

6. Bottomlry, C \& Rymer, J; (2008): Obstetrics and Gynecology: Perspectives on sexual and reproductive health, First Edition, Volume 36(5): 192.

7. Egyptian Demographic Health Survey EDHS (2008): Egyptian Demographic Health Survey, Maternal Health Care, 300-320.

8. Eswi, A\& Khalil, A. (2012): Health locus of control among low risk and high risk pregnant women, World applied sciences journal (18) (4): 462-471.

9. Goodwin, J.,W., Dunne, J.,T., Thomas, B., W., (2009): Antepartum identification of the fetus at risk. Canada Medical Journal, 01:458-64.

10. Hodnett, E. D. (2009): Continuity of caregivers for care during pregnancy and childbirth. Cochrane Database Of Systematic Reviews, (1),

11. Habib, F; Hanafi, M. and Sagheer, A. (2009): Antenatal care in primary health care centers, Madina, Saudi Arabia. Bull. Alex.Fac.Med.45. No(3).

12. Jacob, A; (2009): Comprehensive text book of midwifery: Epidemiol Community Health Journal, Volume 58: 426-433.

13. Klossner, N. and Hatfield, N. (2010): Introductory Maternity \& Pediatric Nursing: Routine Investigation for pregnant women, unit (III), 2nd edition, Lippincott Williams \& Wilkins, : 135.

14. Kalaivani, K., (2009): consequences of anemia in pregnancy. Indian J Med Res 130, : 628-633.

15. Kashani, E; Hassan, A; Ameri, M., A;(2012): the Rate of the prevalence of high risk pregnancies and the the results on pregnant mothers and the effect on parameters after the birth .Advances in envirnmental Biology, vol 6(3): 1319-1324.

16. Nbaber, $P$ and Ckenny, $L$ (2011): Obstetrics by ten teachers: antenatal obstetrics 
complications, ch(8), 19th edition, printed in India, 85-108.

17. Oyibo, P., G; Ebeige, P., N; Nwonwu, E., $\mathrm{U}$;(2011): Assessment of the risk status of pregnant women presenting for antenatal care in a rural health facility in Ebonyi state, South Eastern Nigeria, North American Journal of medical sciences,2011 september.volume 3.No.9, www.najms, org:424-427.

18. Tebeu, P., M; Foumane, P; Robinsonmba; Fosso,G; Biyagea, P., T; Fomulu, J., N; (2011): Risk factors for Hypertension disorders in pregnancy: A report from the Maroua regional Hospital, Cameroon. J reprod infertile, vol 12 (3): 227-234.

19. Tuladhar H, Dhakal N, NjoG. (2011): Impact of Antenatal care on maternal and perinatal outcomes A study at Nepal Medical College Teaching Hospital. Vol 6(2): 37-43.

20. Tran, T., K; Gttvall, K; Nguyen, H., D; Ascher, H and Maxpetzold, (2012): Factors associated with antenatal care adequacy in rural and urban context- results from two health and demographic surveillance sites in Vietnam. http:// www.biomedcentral.com/14726963/12/40.

21. Upadhyay. C; Koregol, M; Bulusu, $\mathbf{R}$ and Nishashah, S., D. (2013): Obstetric outcomes of pregnancies following abortions. Journal of evolution of Medical and Dental sciences/ vol (2), issue 31: 5755- 5758

22. WHO. (2008): Antenatal care in developing countries: promises, achievements and missed opportunities and analysis of trends, levels and differentials 1990-2001.

23. WWW. WHO. (2009, 2010) int/topics/pregnancy/en/maternal health/en.

24. Wong, D. and Perry, Sh., (2008): Maternal Child Nursing Care: Assessment for risk factors, Unit (3) Pregnancy, 3rd edition, Churchill Livingstone: 212-213.

25. Weiner, R; Ronsmans, C; Dorman, E., d; Jilo, H; Muhoro, A and Shulman, C. (2003): Labor complications remain the most important risk factors for perinatal mortality in rural Kenya. Bulletin of the World Health Organization, vol 81 (7).

26. Zareen, N; Nagvi, S; Majid, $\mathbf{N}$ and Fatima, $\mathbf{H}$. (2009): Perinatal outcomes in high risk pregnancies, Journal of the college of phyicians and surgeons Pakistan, vol.19 (7): 432-435. 